\title{
A Hélice Quíntupla como Motor Propulsor da Inovação e Desenvolvimento de Anápolis, Goiás, Brasil
}

A inovação é parte fundamental para alavancar o crescimento e desenvolvimento econômico sustentável de uma nação. Até o final do século passado (XX), a premissa básica que sustentava a maioria dos sistemas nacionais de inovação era que as descobertas e invenções científicas levariam naturalmente ao desenvolvimento econômico e, portanto, ao avanço da sociedade ${ }^{1}$.

No entanto, uma nova abordagem tem ganhado destaque na última década, onde os resultados de pesquisa devem ser legitimados junto a sociedade civil, para criar inovações e crescimento sustentável ${ }^{2}$. Trata-se da hélice quíntupla, que abrange o $\theta$ modelo da hélice tríplice da inovação, baseada na Industria, Universidade (Academia) e Governo, bem como, a participação ativa da sociedade civil, que são os consumidores e usuários da inovação, portanto, parte interessada no processo de inovação regional, e tudo isso levando em consideração o ambiente natural da sociedade para a produção do conhecimento e da inovação. Sendo a assim, a hélice quíntupla é constituída pela indústria, universidade, governo, sociedade e os ambientes naturais ${ }^{3,4}$ (Figura 1).

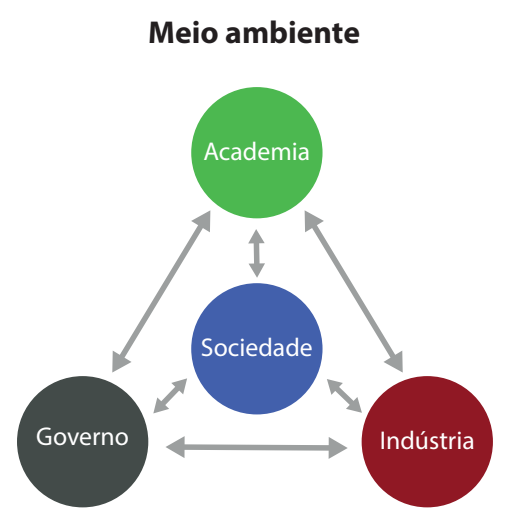

Figura 1: Modelo de hélice quíntupla proposto originalmente por Carayannis, Barth e Campbell (2012).
Apesar do enfoque político e do investimento feito em pesquisa e inovação em âmbito nacional ao longo das três últimas décadas, a comparação e aferição dos polos regionais de inovação no Brasil ainda permanecem limitadas. A mensuração do nível de inovação e da interação entre os diferentes atores no contexto local e regional geralmente é feita por meio de estudos observacionais e às vezes na forma de painéis de avaliação regional, mas sempre utilizando um número limitado de indicadores, o que acaba tornando a compreensão da dinâmica de inovação e a formulação de políticas para apoiar a inovação local e regional um verdadeiro desafio.

Nesse sentido, universidades, governo e indústria da cidade de Anápolis - que é um dos principais polos de desenvolvimento no Estado de Goiás - tem buscado mecanismos para superar o déficit de inovação e incentivar o desenvolvimento tecnológico. Dentre as medidas podemos destacar a participação no grupo Aliança pela Inovação, composto por diversas entidades do Estado de Goiás, na tentativa de aproximar o setor industrial - através da FIEG - e as universidades.

No âmbito da Universidade Evangélica de Goiás (UniEVANGÉLICA), diversas medidas tem sido adotadas afim de promover a colaboração da hélice quíntupla, em especial junto à indústria farmacêutica, para superar o déficit de inovação e apoiar o desenvolvimento de novos medicamentos. Uma das iniciativas foi a criação do Mestrado Profissional em Ciências Farmacêuticas da UniEVANGÉLICA, cuja primeira turma teve início em 2020, onde os pesquisadores, e os alunos - provenientes principalmente da Industria Farmacêutica do Distrito Agroindustrial de Anápolis (DAIA) - trabalham em projetos de pesquisa que visam criar um ambiente que estimula a inovação e apoie o compartilhamento dos conhecimentos 
gerados, desde a pesquisa em estágio inicial até os estágios mais avançados.

A colaboração entre os diferentes atores é fundamental para o sucesso e necessária para atender à necessidade de inovação e aos requisitos cada vez mais exigentes de pesquisa e regulamentação. O ecossistema ainda pouco estudado, que foi desenvolvido na cidade de Anápolis, compreende quatro fatores principais: um sistema educacional consistente e confiável, localização geográfica privilegiada, próxima a dois importantes centros populacionais brasileiros (Goiânia e Brasília), incentivos fiscais e infraestrutura. Esses fatores tem contribuído para que empresas, principalmente da indústria farmacêutica, se instalem no município, o que acabará propiciando a consolidação de um ecossistema de Pesquisa e Desenvolvimento - P\&D na cidade de Anápolis, levando ao desenvolvimento tecnológico e inovações transformacionais. O sucesso contínuo desse ecossistema depende do compromisso e apoio de todos os parceiros envolvidos na hélice tripla, a fim de pôr em funcionamento a hélice quíntupla.

\section{Referências}

1. Schütz F, Heidingsfelder ML, Schraudner M. Co-shaping the Future in Quadruple Helix Innovation Systems: Uncovering Public Preferences toward Participatory Research and Innovation. She. Ji. J. Des. Econ. Innov. 5, 128-146 (2019).

2. Roman M, Varga H, Cvijanovic V, et al. Quadruple Helix Models for Sustainable Regional Innovation: Engaging and Facilitating Civil Society Participation. Econ. 8, 48 (2020).

3. Carayannis EG, Barth TD, Campbell DF. The Quintuple Helix innovation model: global warming as a challenge and driver for innovation. J. Innov. Entrep. 1, 1-12 (2012).

4. Carayannis EG, Rakhmatullin R. The Quadruple/Quintuple Innovation Helixes and Smart Specialisation Strategies for Sustainable and Inclusive Growth in Europe and Beyond. J. Knowl. Econ. 52, 212-239 (2014).

\section{Osmar N. Silva ${ }^{1,2}$}

\begin{abstract}
${ }^{1}$ Mestrado Profissional em Ciências Farmacêuticas, Universidade Evangélica de Goiás, UniEVANGÉLICA, Av. Universitária, km 3,5, Cidade Universitária, s/n, 75083-515, Anápolis-GO, Brasil.

${ }^{2}$ Nucleo de Inovação Tecnológica da Universidade Evangélica de Goiás, UniEVANGÉLICA, Rua Dr. Osvaldo Cruz, qd. 14 - lt. 10 Cidade Universitária, 75074-810, Anápolis - GO, Brasil
\end{abstract}

E-mail: osmar.silva@ppgs.unievangelica.edu.br 